\title{
Assessment of slip resistance under footwear materials, tread designs, floor contamination, and floor inclination conditions
}

\author{
Kai Way Li ${ }^{\mathrm{a} *}$, Chih-Yong Chen ${ }^{\mathrm{b}}$, Ching Chung $\mathrm{Chen}^{\mathrm{c}}$, Liwen $\mathrm{Liu}^{\mathrm{b}}$ \\ ${ }^{a}$ Department of Industrial Management, Chung Hua University, Hsin-Chu, Taiwan, ROC \\ ${ }^{\mathrm{b}}$ Institute of Occupational Safety and Health, Taipei, Taiwan, ROC \\ ${ }^{c}$ Department of Information Management, Hsing Wu College, Taipei, Taiwan, ROC
}

\begin{abstract}
Slip and fall incidences are common in our daily lives. They are not only important environmental safety issues but also important occupational safety and health problems. The purpose of this study was to use the Brungraber Mark II to measure the friction so as to investigate the effects of the shoe sole, surface condition and the inclined angle of the floor and their interactions on friction coefficient. The results of the study showed the effects of all the main factors and their interactions were significant $(p<0.001)$. Engineering designs \& ergonomic interventions in slip \& fall prevention should take these factors in full consideration.
\end{abstract}

Keywords: slips \& falls, friction measurements, tread design, contamination

\section{Introduction}

Slips and falls create safety problems on workplaces worldwide [1-3]. The Health and Safety Executive statistics [4] in the UK revealed that a third of the major occupational incidences were the results of slips or trips. In the USA, the percentage of workers' compensation claim for falling on the same level ranged from $7 \%$ to $44 \%$ across industry groups [3]. The estimated annual expenditures of falls per employed worker were $\$ 300$ and \$560 US Dollars for the trucking and construction industries. Even the restaurant industry suffered an annual expenditure of $\$ 129$ US Dollars per worker for falls. In Taiwan, there were 2,274 falling-related injury cases in 2008 which accounted for $17.6 \%$ of all occupational injuries [5]. Slips and falls also create burden for people in their daily lives. Official statistics in Taiwan [6] showed that falls resulted in injuries required for hospital visit more than any other incidences for children 12 years old or younger. Falls were also the leading causes of unintentional injuries which required for hospital visit for senior citizens.

Floor slipperiness is a major indicator in quantifying the risk of slips \& falls and friction measurement is one of the major approaches to identify floor slipperiness. Footwear, floor, and surface condition may affect the friction on the floor. The purpose of this study was to study the friction at the footwear-floor interface under different footwear materials, floor surfaces and the inclined angles of the floor.

\section{Methods}

A Brungraber Mark II slipmeter was used for friction measurements. The standard test method for the BM II proposed by the American Society of Testing and Materials [7] was adopted. In addition, the protocol in judging a slip or non-slip suggested by Chang [8] was used. To conduct friction measurements on an inclined surface, a metal rig to accommodate the Brungraber Mark II was adopted. This rig (see Figure 1) allows adjustment of the floor angle ranged from 0

\footnotetext{
*Corresponding author. Email: kai@chu.edu.tw
} 


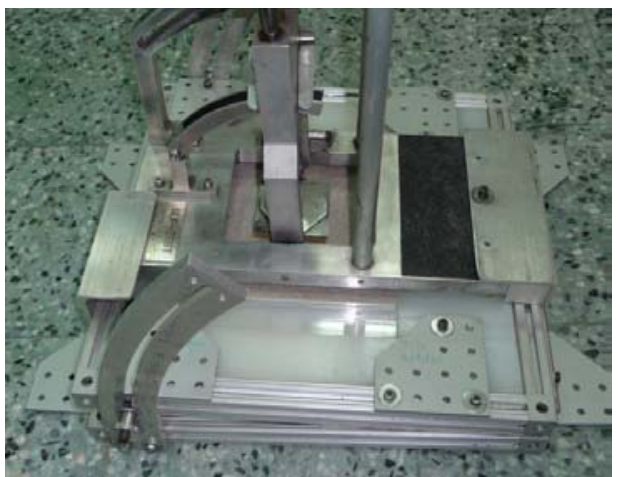

Figure 1 Adjustable ramp for friction measuremnt

${ }^{\circ}$ to $45^{\circ}$. Three inclined angles were tested: $0^{\circ}, 5^{\circ}$, and $10^{\circ}$. Friction measurements were conducted in descending direction.

Three contamination conditions were tested: dry, wet, and glycerol-contaminated conditions. For dry condition, clean dry floor was measured. For wet surface, water of $10 \mathrm{ml}$ was applied on the floor. The same amount of water was replenished during repetitive strike of the footwear pad on the floor. For glycerol contaminated condition, glycerol of $3 \mathrm{ml}$ was applied evenly on the testing area on the floor. The footwear samples included a flat composite rubber pad, a treaded composite rubber pad, a flat Neolite, and a treaded Neolite. The dimensions $(\mathrm{mm})$ of the tread for both the treaded rubber and Neolite pads are shown in Figure 2. The Shore-A hardness for the composite rubber and the Neolite were $69.14( \pm 0.09)$

and $89.51( \pm 0.01)$, respectively. A ceramic floor sample was used. The floor roughness $\left(\mathrm{R}_{\mathrm{a}}\right)$, measured using a Mitutoyo ${ }^{\circledR}$ Surftest 301 profilometer, was 11 $( \pm 1.00) \mu \mathrm{m}$.

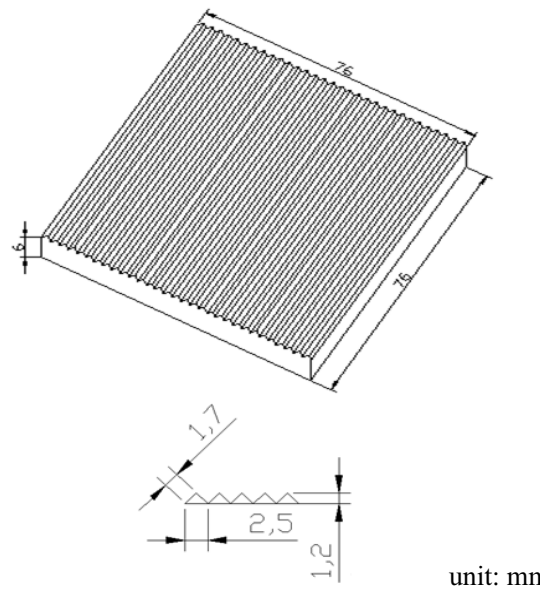

Figure 2 Dimensions of the tread
A three-factor experiment was designed. The factors of the study included footwear, contamination condition, and floor inclination angle. The dependent variable was the coefficient of friction (COF). Six samples were collected for each treatment. There were a total of 216 trials $(4 \times 3 \times 3 \times 6=216)$. Analysis of variance (ANOVA) was performed. Duncan's multiple range tests were also performed if a factor was found significant at $\alpha=0.05$. Statistical analyses were conducted using the SPSS ${ }^{\circledR} 14.0$ software.

The temperature and humidity during data collection were $21.5^{\circ} \mathrm{C}$ and $57 \%$, respectively.

\section{Results}

The results of the analysis of variance (ANOVA) indicated that all the main factors and all the two-way and three-way interaction effects were statistically significant $(p<0.001)$. For the contamination conditions, the dry floors had significantly $(p<0.05)$ highest mean COF (0.85) among all contamination conditions. The mean COF of the wet condition was the next $(0.44)$ and the glycerol condition had the lowest (0.08). For footwear samples, the flat composite had the significant $(p<0.05)$ highest COF $(0.5)$, next was the treaded Neolite $(0.49)$, the next was the treaded composite rubber (0.43), and the last was the flat Neolite $(0.41)$. For the inclination angle, the overall mean COF for the $0^{\circ}, 5^{\circ}$, and $10^{\circ}$ were $0.48,0.46$, and 0.43 , respectively. On dry floor, the mean COF for the $0^{\circ}, 5^{\circ}$, and $10^{\circ}$ were $0.87,0.85$, and 0.83 , respectively. On wet floor, the mean COF for the $0^{\circ}, 5^{\circ}$, and $10^{\circ}$ were $0.46,0.46$, and 0.40 , respectively. On glycerol contaminated floor, mean COF for the $0^{\circ}, 5^{\circ}$, and $10^{\circ}$ were $0.11,0.08$, and 0.04 , respectively.

Table 1 shows the Duncan's multiple range test results for footwear. The flat rubber has significantly $(p<0.05)$ the highest COF than all other footwear pads, next with the treaded Neolite, then the treaded rubber, and finally the flat Neolite.

Table 2 shows the Duncan's multiple range test results for surface condition. The dry surface has significantly $(p<0.05)$ the highest COF than all other conditions, next with the wet condition, and finally the glycerol contaminated condition. 
Table 1

Duncan's multiple range test results for footwear

\begin{tabular}{lrr}
\hline footwear & COF & $\begin{array}{r}\text { Duncan's } \\
\text { grouping }\end{array}$ \\
\hline Flat Neolite & 0.41 & $\mathrm{~A}$ \\
Treaded rubber & 0.43 & $\mathrm{~B}$ \\
Treaded Neolite & 0.49 & $\mathrm{C}$ \\
Flat rubber & 0.50 & $\mathrm{D}$ \\
\hline
\end{tabular}

Note: different letters in Duncan's grouping indicate they are different significantly $(p<0.05)$.

Table 2

Duncan's multiple range test results for surface conditions

\begin{tabular}{lrr}
\hline surface & COF & $\begin{array}{r}\text { Duncan's } \\
\text { grouping }\end{array}$ \\
\hline Glycerol & 0.08 & $\mathrm{~A}$ \\
Wet & 0.44 & $\mathrm{~B}$ \\
Dry & 0.85 & $\mathrm{C}$ \\
\hline
\end{tabular}

Note: different letters in Duncan's grouping indicate they are different significantly $(p<0.05)$.

Table 3 shows the Duncan's multiple range test results for inclined angle of the floor. The flat floor $\left(0^{\circ}\right)$ has significantly $(p<0.05)$ the highest COF than all other inclined angle, next with the $5^{\circ}$, and finally the $10^{\circ}$ inclined angle.

Table 3

Duncan's multiple range test results for surface conditions

\begin{tabular}{lrr}
\hline Inclined angle & COF & $\begin{array}{r}\text { Duncan's } \\
\text { grouping }\end{array}$ \\
\hline $10^{\circ}$ & 0.43 & $\mathrm{~A}$ \\
$5^{\circ}$ & 0.46 & $\mathrm{~B}$ \\
$0^{\circ}$ & 0.48 & $\mathrm{C}$ \\
\hline
\end{tabular}

Note: different letters in Duncan's grouping indicate they are different significantly $(p<0.05)$.

\section{Conclusion}

Friction measurements were conducted under footwear, surface condition, and inclination condition of floor. The results of the study indicated that footwear sample, floor contamination condition, and in- clination condition were all significant factors affecting the COF. The results were consistent with the findings in the literature [9-11]. Selection and design of shoe sole is important in the prevention of slipping $\&$ falling. In addition, large ramp angle could lead to higher risk of slips \& falls. Keeping the floor dry and have a good housekeeping are always helpful in the prevention of slipping \& falling.

\section{Acknowledgments}

The authors thank Der Lin Tseng, a graduate student of the Department of Industrial Management at Chung Hua University, for his assistance in the study.

\section{References}

[1] J. M. Miller, "Slippery" work surface: Toward a performance definition and quantitative coefficient of friction criteria. Journal of Safety Research 14 (1983), 145-158.

[2] M. Tisserand, Progress in the prevention of falls caused by slipping. Ergonomics 28 (1985), 1027-1042.

[3] T.B. Leamon, \& Murphy, P. L., Occupational slips and falls : more than a trivial problem. Ergonomics 38(3) (1995), 487498.

[4] Health and Safety Executive, The assessment of pedestrian slip risk- the HSE approach, technical report, 2004.

[5] Council of Labor Affairs (CLA), Annual Reports of Labor Inspections. Taipei, Taiwan, ROC., 2009.

[6] Bureau of Health, Bureau of Health Promotion Annual Report, Department of Health, Executive Yuan, Taiwan, 2008.

[7] American Society for Testing and Materials, F-1677-05. Standard method of test for using a portable inclinable articulated strut slip tester (PIAST), Annual Book of ASTM Standards. vol. 15.07. West Conshohochen, PA, American Society for Testing and Materials, 2005.

[8] W.R. Chang, The Effect of Slip Crierion and Time on Friction measurement, Safety Science, 40(2002), 593-611.

[9] K.W. Li, \& C.J. Chen, Effect of tread groove orientation and width of the footwear pads on measured friction coefficients. Safety Science 43 (2005), 391-405.

[10]K.W. Li, W-R Chang, J-C Wei, \& C-H Kou, Friction measurements on ramps using the Brungraber Mark II slipmeter. Safety Science 44 (2006), 375-386.

[11]D. P. Manning, \& C. Jones, The effect of roughness, floor polish, water, oil and ice on underfoot friction: current safety footwear solings are less slip resistant than microcellular polyurethane. Applied Ergonomics 32 (2001), 185-196 